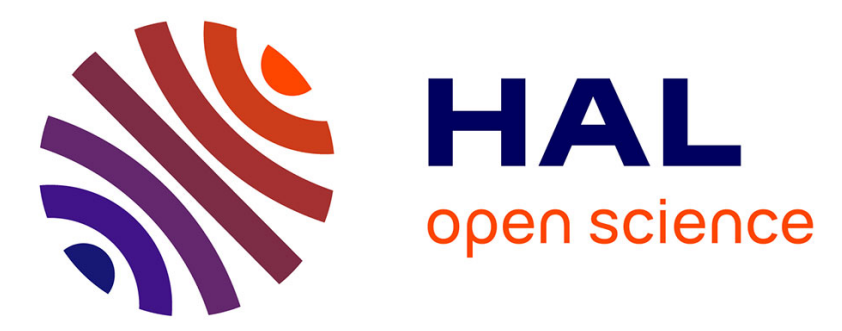

\title{
Impact of administration of vancomycin or linezolid to critically ill patients with impaired renal function
}

O. Rodriguez Colomo, F. Álvarez Lerma, M.I. González Pérez, J-M. Sirvent, M. García Simón

\section{- To cite this version:}

O. Rodriguez Colomo, F. Álvarez Lerma, M.I. González Pérez, J-M. Sirvent, M. García Simón. Impact of administration of vancomycin or linezolid to critically ill patients with impaired renal function. European Journal of Clinical Microbiology and Infectious Diseases, 2011, 30 (5), pp.635-643. 10.1007/s10096-010-1133-6 . hal-00659046

\section{HAL Id: hal-00659046 \\ https://hal.science/hal-00659046}

Submitted on 12 Jan 2012

HAL is a multi-disciplinary open access archive for the deposit and dissemination of scientific research documents, whether they are published or not. The documents may come from teaching and research institutions in France or abroad, or from public or private research centers.
L'archive ouverte pluridisciplinaire HAL, est destinée au dépôt et à la diffusion de documents scientifiques de niveau recherche, publiés ou non, émanant des établissements d'enseignement et de recherche français ou étrangers, des laboratoires publics ou privés. 
Impact of administration of vancomycin or linezolid to critically ill patients with impaired renal function

O Rodriguez Colomo ${ }^{\mathrm{a}}$, F Álvarez Lerma ${ }^{\mathrm{b}}$, MI González Pérez ${ }^{\mathrm{c}}$, J-M Sirvent ${ }^{\mathrm{d}}$, M García Simón ${ }^{\mathrm{a}}$ and the "Study Group of Infection in Critical Patients"*

${ }^{a}$ Department of Intensive Medicine. Hospital Clínico Universitario. Valencia.

${ }^{\mathrm{b}}$ Department of Intensive Medicine. Hospital Universitario del Mar. Barcelona.

${ }^{c}$ Department of Intensive Medicine. Hospital de León. León.

${ }^{\mathrm{d}}$ Department of Intensive Medicine. Hospital Josep Trueta. Girona.

*Members of this group are listed at the end of the paper.

Correspondence: $\quad$ Oscar Rodríguez Colomo

Servicio de Medicina Intensiva

Hospital Universitario de Valencia

C/ Blasco Ibáñez, 17.

46010 Valencia. Spain.

E-mail: orcolomo@gmail.com

Keywords: Linezolid, Vancomycin, Renal failure, ICU.

The results of this study have previously been reported to the 44th National Congress of the Spanish Society of Intensive and Critical Medicine and Coronary Units (SEMICYUC), held in Valladolid on June 2009 


\section{Abstract}

Objective: To assess the impact on renal function of vancomycin (VAN) versus linezolid (LZD) in patients with renal failure $(\mathrm{RF})$ admitted to intensive care units.

Materials and methods: Multicenter, retrospective, comparative cohort study. Renal failure's patients were treated with VAN or LZD for proven or suspected infections by multiresistant Gram-positive cocci. Changes in plasma creatinine levels and creatinine clearance at the start and end of treatment were used as endpoints.

Results: 147 patients treated with VAN (Group A =68) or LZD (Group B =79). Group B included more patients with diabetes mellitus [9 (13.2\%) vs. $25(31.6 \%)$ p.007], septic shock [39 (57.4\%) vs. $60(75.9 \%)$ p.013] and greater RF (mean $\mathrm{ClCr} 42.24 \mathrm{ml} / \mathrm{min}$ vs. $37.57 \mathrm{ml} / \mathrm{min}$, p.04). Renal function improved in patients from both groups who did not require renal replacement therapy. A greater improvement was seen in group B [percent decrease in $\mathrm{Cr}(27.94$ vs. 9.48, p.02) and percent increase in $\mathrm{ClCr}$ (95.96 vs. $55.06, \mathrm{p} .05)]$.

In Group A, 9 patients (13.2\%) experienced an antibiotic-related increase in RF, and antibiotic was discontinued in five patients due to adverse effects.

Conclusion: It is reasonable to avoid use of VAN in critically ill patients with acute renal failure. 


\section{Introduction}

Multiple epidemiological studies, including those conducted at intensive care units (ICUs), show a significant increase in infections caused by Gram-positive cocci (GPCs), including their multiresistant strains (MR-GPCs) (1-6). In Spain, according to data from the National Study of Nosocomial Infection Surveillance (ENVIN), the presence of methicillin-resistant (MRSA) Staphylococcus aureus (SA) in ICU-acquired infections has gradually increased, and SA accounted in 2006 for $4.6 \%$ of all isolates from ICU-acquired infections (2). This proportion decreased in 2008 to $2.22 \%$, or $25 \%$ of all SAs identified (2). On the other hand, resistance of coagulase-negative staphylococci (CNS) to methicillin continues to be higher than $80 \%$. This epidemiological situation has led to an increased use of antibiotics active against these organisms, such as vancomycin (VAN) (7-8) and linezolid (LZD). Tigecycline, a drug of the glycylcycline class, and daptomycin, a macrocyclic lipopeptide, have recently been added to this group of drugs. VAN and LZD are the drugs most commonly used for critically ill patients, despite the fact that use of VAN is greatly controversial (9-15). In addition to tolerability and renal toxicity problems, a high treatment failure rate in severe infections has been reported for VAN, probably related to its poor tissue penetration in the lung, bone tissue, central nervous system (CNS), and inflammatory fluids (16-20). This requires use of higher doses, with the resultant increase in adverse events, one of the most significant of which is renal function impairment (21-26). Despite these limitations, this glycopeptide continues to be widely used at Spanish ICUs. The possibility of monitoring VAN plasma levels and adjusting its dosage based on creatinine clearance has probably promoted use of the drug. However, the clinical impact of this decision is not known, and this study was therefore intended to assess the temporal changes in renal function in patients with biological criteria of renal failure (RF) treated with VAN versus LZD for documented or suspected infections by MR-GPCs.

\section{Materials and methods}

A multicenter, retrospective, observational study was conducted in 17 Spanish ICUs. Data from patients admitted to the participating ICUs in 2006 were retrospectively collected.

All patients over 18 years of age admitted to an ICU who were administered VAN or LZD (initially or as rescue treatment), alone or combined with other antimicrobial drugs, for proven or suspected infections by MR-GPCs in any site and who had renal impairment and were not subject to hemodialysis or any other renal replacement therapy (RRT) before or at the start of treatment were enrolled into the study. RF was defined as serum creatinine $(\mathrm{Cr})$ levels higher than $1.5 \mathrm{mg} / \mathrm{dL}$ and $/$ or $\mathrm{Cr}$ clearance $(\mathrm{ClCr})<60 \mathrm{ml} / \mathrm{min}$, as estimated using the Cockcroft-Gault equation (27).

Exclusion criteria included age under 18 years, use of VAN or LZD as prophylaxis, use of any RRT before or at treatment start, absence of renal function monitoring procedures, use of VAN or LZD for less than 3 days, and use of teicoplanin as initial treatment.

A comparative analysis was made of the groups of patients treated with VAN (Group A) and with LZD (Group B). Data collected included demographic characteristics, comorbidities, immunocompetence, ICU and hospital stay, mortality, reason for admission, infection site and microorganisms involved, type of treatment (empirical or specific), and reasons for treatment discontinuation. Infection severity was assessed both at admission and treatment start (APACHE II) (28), and infection was classified as sepsis, severe sepsis, and septic shock based on Roger C. Bone criteria (29). Cr and glomerular filtration rate (GFR) values, dosage used, and concomitant nephrotoxic medication (amikacin, tobramycin, gentamicin, colistin, acyclovir, tacrolimus, cyclosporine, and foscarnet) were also recorded during treatment. In VANtreated patients, administration form (continuous or intermittent) and plasma levels of the drug (when measured) were recorded. Finally, RRTs performed during treatment were recorded, as well as their adverse effects and therapeutic result. An effectiveness analysis was performed on the complete intentionto-treat (ITT) sample and on the clinically evaluable population (CEP), defined as patients with a documented diagnosis of GPC infection.

Immunosuppressed patients were defined as those administered corticosteroid therapy (methylprednisolone > $40 \mathrm{mg} /$ day for longer than 15 days) and/or treated with other immunosuppressants.

SA and CNS resistant to methicillin and/or VAN and VAN-resistant enterococci were considered as MRGPCs. Clinical cure was defined as resolution of infection with no presence of signs or symptoms 
associated to the original infection, and microbiological eradication as complete eradication of the initial microorganisms. Treatment for at least three days was required to assess treatment failure.

To assess the impact of antibiotic therapy on renal function, patients not requiring any RRT during or within one week of therapy were analyzed. Patients who required RRT were separately analyzed. Plasma Cr levels and GFR were compared at both treatment start and end, while percent change in Cr and GFR was compared during treatment. This percentage was obtained using the following formula: $\mathrm{Cr}$ at treatment end - $\mathrm{Cr}$ at treatment start / $\mathrm{Cr}$ at treatment start. Percent change in GFR was estimated using the same formula.

Statistical analysis: To assess differences in variables analyzed in both study arms, distribution of tested parameters was compared between the treatment groups using a Chi-square test for homogeneity of proportions in qualitative variables, and a Student's $t$ test for independent quantitative variables. A value of $\mathrm{p}<0.05$ was considered statistically significant. The nominal significance level was not adjusted for multiplicity.

\section{Results}

A total of 147 patients treated with VAN (68, Group A) or LZD (79, Group B) for documented or suspected infections by MR-GPCs were enrolled into the study. Mean age of patients analyzed was 64 years (SD 13.98), and 70.7\% were males. Mean APACHE II on admission was 21.71 (SD 7.36). Of all patients, $67.1 \%$ came from other hospital departments and $64.6 \%$ were medical patients. Sepsis was the most common reason for ICU admission (33.8\%). ICU mortality was high, and hospital mortality was $50.3 \%$. Table 1 shows the demographic characteristics, severity, admission diagnosis, and concomitant diseases of patients by treatment received. There were no significant differences between both groups. Concomitant diseases included chronic obstructive pulmonary disease and diabetes mellitus, which was more common in Group B (p.007).

Table 2 breaks down infections by type, location, and systemic response. Nosocomial infections were most common, accounting for $73 \%$ of all infections, with no differences between both treatment groups. Infections were quite serious, as shown by a mean APACHE II score of 21.88 points (SD 17.29) at the start of treatment. Septic shock occurred in $67.3 \%$ of all patients and in a greater percentage of patients given LZD (p.013), while a higher proportion of sepsis with no organ failure was found in VAN-treated patients (p.002).

One or more Gram-positive bacteria were isolated in 97 patients $(65.9 \%)$. SA (40.2\%) and CNS (32.9\%) were the most commonly found microorganisms (Table 3). Polymicrobial infections associated to Gramnegative bacilli were found in $24.7 \%$ of patients, with no difference between the two treatment groups analyzed (Table 3). VAN and LZD were administered in most cases empirically (76.2\%) and combined with other antimicrobials, most commonly broad-spectrum antibiotics (87.1\%). Combinations with piperacillin/tazobactam and carbapenems were most common. No differences were found between the groups compared. The duration of the treatment was longer in Group B [11.27 (SD 8.98) vs. 7.44 days (SD 4.17) p.002]. VAN was continuously administered to 15 patients (22.1\%). Steady state plasma levels of VAN were measured in $10(66.7 \%)$ of these patients [mean: $21.16 \mu \mathrm{g} / \mathrm{ml}$ (SD 6.56)]. In $18(34 \%)$ of the 53 patients on intermittent administration, trough levels were measured [mean: $29.26 \mu \mathrm{g} / \mathrm{ml}$ (SD 13.47)].

At treatment start, Group B patients had a greater renal function impairment than Group A patients, as shown by higher mean $\mathrm{Cr}$ levels (2.30 vs. 2.11) and significantly lower $\mathrm{ClCr}$ values (37.57 vs. 42.24 , p.04). During treatment, RRTs were used in $18 / 147$ patients $(12.2 \%)$. Continuous venovenous hemodiafiltration (CVVHDF) was the RRT used in 14 of these patients. Renal function support measures were used more frequently in Group B [14/79 (17.7\%)] as compared to Group A [4/68 (5.9\%)], and CVVHDF was indicated in most cases $(12 / 14 ; 85.7 \%)$. Table 4 details demographic characteristics, severity, organic impact of infections, mortality, and renal function changes over time in these patients. Chronic renal failure was diagnosed in $33.3 \%(6 / 18)$ of the patients, and was more prevalent in the Group B $(35.7 \%$ vs. $25 \%)$, even though the difference was not statistically significant. Mean APACHE II score was $24.22,77.8 \%$ were in septic shock, and mortality was $77.8 \%$. There were no significant differences between both groups of antibiotic therapy. 
Concomitant nephrotoxic drugs were administered to $27.9 \%$ of patients, with no differences between both groups [17/68 (25\%) vs. 24/79 (30.4\%), p. 29]. Aminoglycosides were most common in both groups [11/17 (63.4\%) vs. $15 / 24(62.5 \%)$ p. 70$]$.

Table 5 shows the changes in plasma Cr levels and GFR from the start to the end of treatment as measured in the 129 patients $(85.8 \%)$ who required no extrarenal clearance techniques during or at the end of treatment. GFR improved during antibiotic therapy in both groups, with a resultant decrease in $\mathrm{Cr}$ levels, but a greater improvement was seen in LZD-treated patients (p.05 and p.02 respectively) (Figure 1). Clinical and microbiological effectiveness was compared by ITT and in the CEP (Table 6). Clinical cure rates were $49.7 \%$ and $67.0 \%$ respectively. They were higher in Group B in both cases, but the difference was not statistically significant. Microbiological eradication rates were $48.3 \%$ and $61.9 \%$. Higher rates were found in Group B, but there were more indeterminate results in Group A.

Twelve (8.2\%) adverse effects related to the antibiotics tested were recorded. Nine (13.2\%) patients treated with VAN had an increased renal impairment which was attributed to drug administration, as compared to none of the patients treated with LZD (p.001). Thrombocytopenia occurred in 3 patients (3.8\%) treated with LZD and in no patient in the VAN group (p.15).

Table 7 shows the reasons for treatment discontinuation. The main reason for stopping treatment was clinical cure $(49.7 \%$ of patients), which occurred in significantly more Group B patients $(55.7 \%$ vs. $42.6 \%$, p.04). Treatment was discontinued for adverse effects in 5 patients, all from Group A (7.4\% vs. $0.0 \%, \mathrm{p} .02)$.

\section{Discussion}

This observational, retrospective study to analyze the impact of use of VAN and LZD in patients with biological criteria of RF showed a better evolution of renal function in critically ill patients with documented or suspected infection by MR-GPCs when treated with LZD as compared to VAN. Although an overall improvement in renal function occurred in both groups, VAN-treated patients had a significantly lower improvement, and $13.2 \%$ of them experienced a worsening in renal function attributable to VAN which required drug discontinuation in half of them. It is currently recommended that VAN trough plasma levels ranging from 15 and $20 \mu \mathrm{g} / \mathrm{ml}$ are achieved, and even higher levels if infection involves the CNS (25-26). This requires use of doses up to $60 \mathrm{mg} / \mathrm{kg} / \mathrm{day}$, which involves a greater risk of renal toxicity. These recommendations have been supported by the results of recent studies showing that minimal inhibitory concentration (MIC) of VAN against SA has increased since the 90s. There are studies reporting an incidence of strains with MIC $>1 \mu \mathrm{g} / \mathrm{ml}$ higher than $50 \%$, which is associated to a decreased therapeutic effectiveness (21-24). In this setting, if VAN administration is decided, MICs of VAN against the pathogens involved would have to be known and VAN plasma levels would have to be monitored, mainly in critically ill patients with severe sepsis, in whom changes in hemodynamics and distribution volume are also common. In our study, reporting use of VAN in some Spanish ICUs in 2006, such levels were measured in few cases (in $66.7 \%$ and $34 \%$ of patients on continuous and intermittent administration respectively), and mean values obtained were in the upper range of recommended concentrations $(21.16 \mu \mathrm{g} / \mathrm{ml}$ and $29.26 \mu \mathrm{g} / \mathrm{ml}$ respectively). These data support the convenience of monitoring VAN levels in these patients when the drug is used, and also the need to consider alternative treatment particularly in severe infections and when the MIC of this antibiotic against SA is unknown or higher than $1 \mu \mathrm{g} / \mathrm{ml}$. While the proportion of patients on hemodialysis was similar in both groups, CVVHDF was used in $15.2 \%$ of patients treated with LZD as compared to $2.9 \%$ of patients treated with VAN (p.01). It should be noted that patients treated with LZD had a greater renal function impairment at baseline, as shown by a lower $\mathrm{ClCr}$ at treatment start (37.57 vs. 42.24, p.04). On the other hand, among Group B patients undergoing RRTs, $35.7 \%$ had chronic renal failure, as compared to $25 \%$ in Group A; although the difference was not statistically significant. Finally, it is very likely that the greater proportion of patients with septic shock in the group treated with LZD (75.9\% vs. 57.4\% LZD vs. VAN, p .013) and the fact that 11 out of the 14 patients in this group receiving RRT were in such hemodynamic situation (78.6\%) influenced the higher rate of CVVHDF which, as known, is a procedure used to remove inflammatory mediators in the systemic inflammatory response syndrome of sepsis.

On the other hand, another aspect worthy of mentioning is the percentage of cases of thrombocytopenia related with the antibiotic treatment $(3.8 \%)$, considering that it was higher than what would have been expected in patients treated with LZD, taken into account the duration of the treatment [11.27 days (SD 
8.98)]. This result could also have been conditioned by a more serious presentation of the infection in this patient group.

ICU and hospital mortality of patients enrolled into this study was high. This was related to the severity of the condition of these patients, as shown by both mean APACHE II (21.88) and impact on organs of infections occurring as severe sepsis/septic shock in $83.6 \%$ of cases. It should be noted that while a greater systemic impact was seen in patients treated with LZD (75.9\% vs. $57.4 \%$ patients in septic shock), there were no differences in mortality.

In the effectiveness analysis by IT and in the CEP, a higher cure rate was seen in LZD-treated patients, but the difference was not statistically significant, probably because of the small size of the sample used to analyze this variable. Analysis of microbiological effectiveness did not provide significant conclusions. Although microbiological eradication rates were significantly higher in Group B, a significantly greater proportion of indeterminate results was found in Group A. On the other hand, an analysis of the reasons for drug discontinuation showed superiority of LZD over VAN. Among LZD patients, there were more cases where treatment was discontinued due to clinical cure $(55.7 \%$ vs. $42.6 \%$, p.04) and less patients with drug discontinuation for adverse effects $(7.4 \%$ vs. $0 \%$, p.02). Both data show the higher effectiveness of LZD as compared to VAN for treating this group of patients with impaired renal function.

Limitations of this study include retrospective data collection, with its inherent limitations. Despite this important consideration, retrospective recruitment was consecutively performed, with a balanced number of patients in both treatment groups included at each hospital. Sample size was adequate for analyzing the primary objective of the study, and although the group treated with LZD included patients who were more seriously ill and, had lower $\mathrm{ClCr}$ values, and a greater proportion of patients with diabetes mellitus, this does not invalidate results because renal function evolved better in this group.

Based on the results of this study, it is reasonable to conclude that use of VAN should be avoided in critically ill patients with acute renal failure. If VAN is used, it is essential to monitor its plasma levels and to ascertain the MICs for the pathogens involved in infection.

\section{References}

1. Vincent JL, Rello J, Marshall J, Silva E, Anzueto A, Martin CD, Moreno R, Lipman J, Gomersall C, Sakr Y, Reinhart K; EPIC II Group of Investigators. International study of the prevalence and outcomes of infection in intensive care units. JAMA. 2009; 302(21): 2323-9.

2. Grupo de Trabajo de Enfermedades Infecciosas de la Sociedad Española de Medicina Intensiva Crítica y Unidades Coronarias. Estudio Nacional de Vigilancia de Infección Nosocomial en Servicios de Medicina Intensiva (ENVIN-UCI). SEMICYUC. En: http://hws.vhebron.net/envin-helics/ (última entrada 29 febrero 2010)

3. Rosenthal VD, Maki DG, Mehta A, Alvarez-Moreno C, Leblebicioglu H, Higuera F, et al; International Nosocomial Infection Control Consortium Members. International Nosocomial Infection Control Consortium report, data summary for 2002-2007, issued January 2008. Am J Infect Control 2008; 36: 627-37.

4. Picazo JJ, Betriu C, Rodríguez-Avial I, Culebras E, Gómez M, López F. Grupo VIRA. Vigilancia de resistencias a los antimicrobianos: estudio VIRA 2006. Enferm Infecc Microbiol Clin 2006; 24 : 617 28.

5. Jones ME, Draghi DC, Thornsberry C, Karlowsky JA, Sahm DF, Wenzel RP. Emerging resistance among bacterial pathogens in the intensive care unit-a European and North American Surveillance study (2000-2002). Annals of Clinical Microbiology and Antimicrobials. 2004; 3: 14. En: http://www.ann-clinmicrob.com/content/3/1/14

6. Álvarez Lerma F, Palomar M, Insausti J, Olaechea P, Cerdá E, Sánchez Godoy J, De la Torre MV; Grupo de Estudio Nacional de Vigilancia de Infección Nosocomial en UCI. Staphylococcus aureus nosocomial infections in critically ill patients admitted in intensive care units. Med Clin (Barc). 2006 May 6; 126: 641-6. 
7. Insausti J. Consumo de antibióticos en medicina intensiva. En: Estudio Nacional de Vigilancia de Infección Nosocomial en UCI (ENVIN-UCI). Ed: Jarpyo Editores SA. Madrid 2002: 129-148.

8. Malacarne P, Rossi C, Bertolini G. GiViTI Group. Antibiotic usage in intensive care units: a pharmaco-epidemiological multicentre study. Journal of Antimicrobial Chemotherapy 2004; 54: 221 224.

9. Rodríguez Colomo O, Álvarez Lerma F, Alvarez Sánchez B, Oltra Chordá R, Barcenilla Gaite F, Cereijo Martín-Grande E, Cuñat de la Hoz J, Martínez Pellús A; Study Group on the use of active antibiotics against multiresistant gram positive cocci in critical patients. Use of antibiotics for the treatment of multiresistant gram positive cocci infections in critical patients. Med Intensiva 2008; 32: 263-71.

10. Rybak MJ, Albrecht LM, Boike SC, Chandrasekar PH. Nephrotoxicity of vancomycin, alone and with an aminoglycoside. J Antimicrob Chemother 1990; 25: 679-87.

11. Goetz MB, Sayers J. Nephrotoxicity of vancomycin and aminoglycoside therapy separately and in combination. J Antimicrob Chemother 1993; 32: 325-334.

12. Ziglam HM, Finch RG. Limitations of presently available glycopeptides in the treatment of Grampositive infection. Clin Microbiol Infect 2001; 7 Suppl 4: 53-65.

13. Iwamoto T, Kagawa Y, Kojima M. Clinical efficacy of therapeutic drug monitoring in patients receiving vancomycin. Biol Pharm Bull 2003; 26: 876-879.

14. Jeffres MN, Isakow W, Doherty JA, Micek ST and Kollef MH. A retrospective analysis of possible renal toxicity associated with vancomycin in patients with health care associated methicillin-resistant Staphylococcus aureus pneumonia. Clin Ther 2007; 29: 1107-15.

15. Lodise TP, Lomaestro B, Graves J, Drusano GL. Larger vancomycin doses ( at least four grames per day) are associated with an increased incidence of nephrotoxicity. Antimicrob Agents Chemother. 2008; 52:1330-6.

16. Pou L, Rosell M, Lopez R, Pascual C. Changes in vancomycin pharmacokinetics during treatment. Ther Drug Monit 1996; 18(2): 149-153.

17. Albanèse J, Léone M, Bruguerolle B, Ayem ML, Lacarelle B, Martin C. Cerebrospinal fluid penetration and pharmacokinetics of vancomycin administered by continuous infusion to mechanically ventilated patients in an intensive care unit. Antimicrob Agents Chemother 2000; 44(5): 1356-8.

18. Georges H, Leroy O, Alfandari S, Guery B, Roussel-Delvallez M, Dhennain C. Pulmonary disposition of vancomycin in critically ill patients. Eur J Clin Microbiol Infect Dis 1997; 16(5): 3858.

19. Lamer C, de Beco V, Soler P, Calvat S, Fagon JY, Dombret MC. Analysis of vancomycin entry into pulmonary lining fluid by bronchoalveolar lavage in critically ill patients. Antimicrob Agents Chemother 1993; 37(2): 281-6.

20. Daschner FD, Frank U, Kümmel A, Schmidt-Eisenlohr E, Schlosser V, Spillner H. Pharmacokinetics of vancomycin in serum and tissue of patients undergoing open-heart surgery. $\mathrm{J}$ Antimicrob Chemother 1987; 19(3): 359-62.

21. Bingen E, Mariani-Kurkdjian P, Nebbad B. Optimal vancomycin serum level in Staphylococcus aureus infections? Med Mal Infect 2006; 36(9): 439-442.

22. Wang G, Hindler JF, Ward KW, Bruckner DA. Incresed vancomycin MICs for Staphylococcus aureus clinical isolated from a university hospital during a 5-year period. Journal of Clinical Microbiology 2006; 44: 3883-6.

23. Sakoulas G, Moise-Broder PA, Schentag J, Forrest A, Moellering RC, Eliopoulos GM. Relationship of MIC and Bactericidal Activity to Efficacy of Vancomycin for Treatment of Methicillin-Resistant Staphylococcus aureus Bacteremia. Journal of Clinical Microbiology 2004; 42: 2398-2402.

24. Soriano A, Marco F, Martínez JA, Pisos E, Almela M, Dimova VP, Alamo D, Ortega M, Lopez J and Mensa J. Influence of vancomycin minimum inhibitory concentration on the treatment of methicillinresistant Staphylococcus aureus bacteremia. Clin Infect Dis 2008; 46:193-200. 
25. Hidayat LK, Hsu DI, Quist R, Shriner KA, Wong-Beringer A. High-dose vancomycin therapy for methicillin-resistant Staphylococcus aureus infections: efficacy and toxicity. Arch Intern Med. 2006; 166: $2138-44$

26. Rybak M, Lomaestro B, Rotschafer JC, Moellering R, Craig W, Billeter M et al. Therapeutic monitoring of vancomycin in adult patients: A consensus review of the American Society of HealthSystem Pharmacists, the Infectious Diseases Society of America, and the Society of Infectious Diseases Pharmacists Am J Health-Syst Pharm. 2009; 66:82-98

27. Cockcroft DW, Gault MH. Prediction of creatinine clearance from serum creatinine. Nephron 1976; 16: 31-41.

28. Knaus WA, Draper EA, Wagner DP, Zimmerman JE. APACHE II: a severity of disease classification system. Crit Care Med 1985; 13(10): 818-29.

29. Bone RC. "American College of Chest Physicians/Society of Critical Care Medicine Consensus Conference: Definitions for sepsis and organ failure and guidelines for the use of innovative therapies in sepsis". Crit Care Med 1992; 20: 864-74.

\section{Statement of conflicts of interest}

This study was conducted with the participation of the "Study Group of Infection in Critical Patients", whose members are listed below. This study was funded by an unrestricted educational research grant from Pfizer Spain (NRA5950008). FAL has received a grant from Gilead, honoraria as lecturer from Pfizer, Wyeth, Sanofi-Aventis, Gilead, MSD, and Novartis, and consultancy fees from Pfizer, Novartis, Wyeth, and Cephalon. ORC has received technical support for research from Wyeth Farma, honoraria as lecturer from Lilly and Pfizer, and consultancy fees from Pfizer.

The Study Group of Infection in Critical Patients consists of the following members:

M I González Pérez, Hospital de León (20 patients); J M Sirvent, Hospital Dr. Josep Trueta, Girona (18 patients); F Esteve Urbano, J Ballus Noguera, Hospital Universitari de Bellvitge, Barcelona (13 patients); F Álvarez Lerma, Hospital del Mar, Barcelona (11 patients); O Rodríguez Colomo, M García Simón, Hospital Clínico Universitario de Valencia (10 patients); M Jiménez Lendinez, Hospital Universitario la Paz, Madrid (10 patients); B Álvarez Sánchez, Hospital General Universitario de Alicante (10 patients); G A Salinas Reyes, P Kot Baixauli, Hospital Universitario La Fe, Valencia (10 patients); J M Nicolás Arfelis, Hospital Clinic de Barcelona (8 patients); M Borges Sa, Hospital Son Llàtzer, Palma de Mallorca (8 patients); J Trenado Álvarez, Hospital Mútua de Terrassa (6 patients); Alejandro Úbeda, Hospital de Valme, Sevilla (5 patients); F Ruiz Ferrón, Hospital de Jaén, Jaén (5 patients); I Catalán Gómez, Xarxa Hospitalaria de Manresa, Barcelona (5 patients); J Carlos Montejo, Hospital 12 de Octubre, Madrid (4 patients); E Yuste Osorio, Hospital Universitario San Cecilio, Granada (2 patients); M Sánchez Palacios, Hospital Universitario Insular de Gran Canaria, Las Palmas de Gran Canaria (2 patients). 
TABLE 1. Demographic and clinical characteristics and concomitant diseases of patients by treatment group.

\begin{tabular}{|c|c|c|c|c|}
\hline & Total $n=147$ & $\begin{array}{l}\text { VAN n }=68 \\
\text { Group A }\end{array}$ & $\begin{array}{l}\text { LZD n }=79 \\
\text { Group B }\end{array}$ & $\mathbf{P}$ \\
\hline Mean age (SD) & $64.07(13.98)$ & $65.06(14.64)$ & $63.22(13.41)$ & .42 \\
\hline Male, n (\%) & $104(70.7)$ & $45(66.2)$ & $49(74.7)$ & .17 \\
\hline Mean APACHE II (SD) & $21.71(7.36)$ & $21.83(7.20)$ & $21.62(7.54)$ & .86 \\
\hline Death at ICU, n (\%) & $57(38.8)$ & $27(39.7)$ & $30(38.0)$ & .48 \\
\hline Death at hospital, n (\%) & $74(50.3)$ & $38(55.9)$ & $36(45.6)$ & .14 \\
\hline \multicolumn{5}{|l|}{ Patient source, n (\%) } \\
\hline Community & $44(30.1)$ & $22(32.4)$ & $22(28.2)$ & \\
\hline Hospital & $98(67.1)$ & $43(63.2)$ & $55(70.5)$ & .40 \\
\hline Long-term facility & $4(2.7)$ & $3(4.4)$ & $1(0.7)$ & \\
\hline \multicolumn{5}{|l|}{ Patient type, n (\%) } \\
\hline Medical & $95(64.6)$ & $47(69.1)$ & $48(60.8)$ & \\
\hline Surgical & $38(25.9)$ & $13(19.1)$ & $25(31.6)$ & \\
\hline Trauma & $10(6.8)$ & $6(8.8)$ & $4(5.1)$ & \\
\hline Coronary & $4(2.7)$ & $2(2.9)$ & $2(2.5)$ & \\
\hline \multicolumn{5}{|c|}{ Admission diagnosis, $\mathrm{n}(\%)$} \\
\hline Cardiovascular disease & $15(10.3)$ & $9(13.2)$ & $6(7.8)$ & \\
\hline Sepsis & $49(33.8)$ & $24(35.3)$ & $25(32.5)$ & \\
\hline Trauma & $8(5.5)$ & $5(7.4)$ & $3(3.9)$ & \\
\hline Respiratory failure & $11(7.6)$ & $3(4.4)$ & $8(10.4)$ & \\
\hline Pneumonia & $19(13.1)$ & $9(13.2)$ & $10(13.0)$ & .95 \\
\hline Pancreatitis & $5(3.4)$ & $1(1.5)$ & $4(5.2)$ & \\
\hline Peritonitis & $8(5.5)$ & $2(2.9)$ & $6(7.8)$ & \\
\hline Postoperative & $5(3.4)$ & $1(1.5)$ & $4(5.2)$ & \\
\hline CNS disease & $12(8.3)$ & $8(11.8)$ & $4(5.2)$ & \\
\hline Other & $13(9.0)$ & $6(8.8)$ & $7(9.1)$ & \\
\hline \multicolumn{5}{|c|}{ Concomitant diseases, $\mathrm{n}(\%)$} \\
\hline Diabetes & $34(23.1)$ & $9(13.2)$ & $25(31.6)$ & .007 \\
\hline Immunodeficiency & $42(28.6)$ & $21(30.9)$ & $21(26.6)$ & .34 \\
\hline Chronic renal failure & $21(14.3)$ & $8(11.8)$ & $13(16.5)$ & .28 \\
\hline COPD & $34(23.1)$ & $19(27.9)$ & $15(19.0)$ & .13 \\
\hline Severe heart failure & $15(10.2)$ & $10(14.7)$ & $5(6.3)$ & .08 \\
\hline Chronic liver disease & $16(10.9)$ & $10(14.7)$ & $6(7.6)$ & .13 \\
\hline Alcoholism & $20(13.6)$ & $10(14.7)$ & $10(12.7)$ & .45 \\
\hline
\end{tabular}

CNS: central nervous system; COPD: chronic obstructive pulmonary disease 
TABLE 2. Infection type, location, and severity by treatment group

\begin{tabular}{|c|c|c|c|c|}
\hline Infection type, n (\%) & $\begin{array}{l}\text { Total } \\
\mathrm{n}=147\end{array}$ & $\begin{array}{l}\text { VAN n = } 68 \\
\text { Group A }\end{array}$ & $\begin{array}{l}\text { LZD n }=79 \\
\text { Group B }\end{array}$ & $\mathbf{P}$ \\
\hline Community-acquired & $39(26.5)$ & $19(27.9)$ & $20(25.3)$ & \\
\hline Hospital-acquired (outside ICU) & $55(37.4)$ & $25(36.8)$ & $30(38.0)$ & .93 \\
\hline ICU-acquired & $53(36.1)$ & $24(35.3)$ & $29(36.7)$ & \\
\hline \multicolumn{5}{|l|}{ Location, n (\%) } \\
\hline VAP & $18(12.2)$ & $9(13.2)$ & $9(11.4)$ & \\
\hline Primary bacteremia & $17(11.6)$ & $8(11.8)$ & $9(11.4)$ & \\
\hline Secondary bacteremia & $16(10.9)$ & $9(13.2)$ & $7(8.9)$ & \\
\hline Vascular catheter infection & $14(9.5)$ & $8(11.8)$ & $6(7.6)$ & \\
\hline Non-VAP & $34(23.1)$ & $13(19.1)$ & $21(26.6)$ & .67 \\
\hline Non-CAUTI & $3(2.0)$ & $2(2.9)$ & $1(1.3)$ & \\
\hline SWI & $20(13.6)$ & $10(14.7)$ & $10(12.7)$ & \\
\hline SSTI & $7(4.8)$ & $4(5.9)$ & $3(3.8)$ & \\
\hline Other locations & $18(12.2)$ & $5(7.4)$ & $13(16.5)$ & \\
\hline \multicolumn{5}{|l|}{ Severity at treatment start } \\
\hline Mean APACHE II (SD)* & $21.88(7.29)$ & $22.54(7.87)$ & $21.31(6.75)$ & .31 \\
\hline Sepsis n $(\%)$ & $24(16.3)$ & $18(26.5)$ & $6(7.6)$ & .002 \\
\hline Severe sepsis, n (\%) & $24(16.3)$ & $11(16.2)$ & $13(16.5)$ & .57 \\
\hline Septic shock, n (\%) & $99(67.3)$ & $39(57.4)$ & $60(75.9)$ & .013 \\
\hline
\end{tabular}

VAP: Ventilator-associated pneumonia

Non-VAP: Non-ventilator-associated pneumonia

Non-CAUTI: Non-catheter-associated urinary tract infection

SSTI: Skin and soft tissue infection

SWI: Surgical wound infection 
TABLE 3. Microorganisms identified in infections included in the study

\begin{tabular}{llll}
\hline Microorganisms & Total n =97 & VAN n = 44 & LZD n = 53 \\
\hline Gram-positive, n (\%) & $97 / 147(65.9)$ & $44 / 97(45,4)$ & $53 / 97(54,6)$ \\
Staphylococcus aureus, MS & $17 / 97(17.5)$ & $7 / 44(15,9)$ & $10 / 53(18,9)$ \\
Staphylococcus aureus, MR & $22 / 97(22.7)$ & $6 / 44(13,6)$ & $16 / 53(30,2)$ \\
Coagulase-negative & $32 / 97(32.9)$ & $13 / 44(29,5)$ & $19 / 53(35,8)$ \\
Staphylococcus & & & \\
Other staphylococci & $2 / 97(2.1)$ & $1 / 44(2,3)$ & $1 / 53(1,9)$ \\
Streptococcus pneumoniae & $5 / 97(5.2)$ & $4 / 44(9,1)$ & $1 / 53(1,9)$ \\
Enterococcus faecalis & $4 / 97(4.1)$ & $4 / 44(9,1)$ & $0 / 53(0,0)$ \\
Enterococcus faecium & $8 / 97(8.2)$ & $5 / 44(11,4)$ & $3 / 53(5,7)$ \\
Other streptococci & $7 / 97(7.2)$ & $4 / 44(9,1)$ & $3 / 53(5,7)$ \\
Associated to GNBs & $24 / 97(24.7)$ & $11 / 24(45,8)$ & $13 / 24(54,2)$ \\
Pseudomonas aeruginosa & $6 / 24(25)$ & $4 / 11(36,4)$ & $2 / 13(15,4)$ \\
Escherichia coli & $4 / 24(16.7)$ & $2 / 11(18,2)$ & $2 / 13(15,4)$ \\
Klebsiella pneumoniae & $3 / 24(12.5)$ & $1 / 11(9,1)$ & $2 / 13(15,4)$ \\
Other GNBs & $7 / 24(29,2)$ & $3 / 11(27,3)$ & $4 / 13(30,8)$ \\
\hline
\end{tabular}

GNBs: Gram-negative bacilli 
TABLE 4. General characteristics and change in renal function of patients undergoing RRT during antibiotic therapy

Demographic characteristics and infection severity and presentation

$\begin{array}{lllll} & \text { Total } \mathbf{n}=\mathbf{1 8} & \text { VAN n = 4 } & \text { LZD n= 14 } & \text { p } \\ \text { Mean age (SD) } & 65.28(10.76) & 69.00(5.77) & 64.21(11.76) & .45 \\ \text { Male, n (\%) } & 14(77.8) & 3(75) & 11(78.6) & .88 \\ \text { Mean APACHE II (SD) } & 24.22(7.53) & 27.25(9.91) & 23.35(6.92) & .37 \\ \text { Severe sepsis, n (\%) } & 3(16.7) & 1(25) & 2(14.3) & .6 \\ \text { Septic shock, n (\%) } & 14(77.8) & 3(75) & 11(78.6) & .88 \\ \text { Death at ICU, n (\%) } & 14(77.8) & 3(75) & 11(78.6) & .88\end{array}$

Concomitant diseases, $\mathrm{n}(\%)$

Diabetes $(\%)$

$\begin{array}{ll}8(44.4) & 3(75) \\ 6(33.3) & 1(25) \\ 5(27.8) & 1(25)\end{array}$

$5(35.7)$

.16

$\mathrm{CRF}(\%)$

$5(27.8)$

$1(25)$

$5(35.7)$

.68

COPD $(\%)$

$\begin{array}{lll}\text { VAN n= 4* } & \text { LZD } \mathbf{n = 1 4} * & \mathbf{p} \\ 3.52(1.60) & 3.36(1.49) & .85 \\ 2.09(0.79) & 2.03(1.40) & .94 \\ -13.68(79.57) & -39.15(30.11) & .57 \\ 30.04(20.93) & 28.23(12.65) & .83 \\ 42.61(14.98) & 60.92(47.99) & .47 \\ 122.17(194.66) & 117.27(137.22) & .95\end{array}$

Change in renal function over time

*Mean (SD) - RRT: Renal replacement therapy - Creat: Creatinine

ClCr: Creatinine clearance - CRF: Chronic renal failure 
TABLE 5. Analysis of change in renal failure in patients undergoing no RRT during or at the end of antibiotic therapy

\begin{tabular}{llll}
\hline $\mathbf{n}=\mathbf{1 2 9}$ & $\mathbf{V A N} \mathbf{n = 6 4}$ & $\mathbf{L Z D} \mathbf{~ n = 6 5 *}$ & $\mathbf{p}$ \\
Creatinine at treatment start & $2.02(1.91)$ & $2.08(0.91)$ & .82 \\
Creatinine at treatment end & $1.65(1.34)$ & $1.40(0.84)$ & .20 \\
Percent change in creatinine & $-9.48(51.92)$ & $-27.94(41.11)$ & .02 \\
$\mathrm{ClCr}$ at treatment start & $43.01(13.44)$ & $39.58(13.34)$ & .14 \\
$\mathrm{ClCr}$ at treatment end & $63.57(41.91)$ & $75.80(56.69)$ & .16 \\
Percent change in $\mathrm{ClCr}$ & $55.06(112.91)$ & $95.96(127.40)$ & .05
\end{tabular}

*Mean (SD) - RRT: Renal replacement therapy - ClCr: Creatinine clearance

\section{TABLE 6. Effectiveness}

\section{Clinical effectiveness in the intention-to-treat population}

$\begin{array}{lllll}\text { n (\%) } & \text { Total n = 147 } & \begin{array}{l}\text { VAN n = 68 } \\ \text { Group A }\end{array} & \begin{array}{l}\text { LZD n = 79 } \\ \text { Group B }\end{array} & \text { p } \\ \text { Cure } & 73(49.7) & 29(42.6) & 44(55.7) & .11 \\ \text { Failure } & 33(22.4) & 20(29.4) & 13(16.5) & \\ \text { Indeterminate } & 41(27.9) & 19(27.9) & 22(27.8)\end{array}$

Microbiological effectiveness in the intention-to-treat population

$\begin{array}{llll}\text { Eradication } & 71(48.3) & 26(38.2) & 45(57.9) \\ \text { Persistence } & 12(8.2) & 5(7.4) & 7(8.9) \\ \text { Indeterminate } & 64(43.5) & 37(54.4) & 27(34.2)\end{array}$

Clinical effectiveness in the clinically evaluable population*

$\begin{array}{lllll}\mathrm{n}(\%) & \text { Total } \mathbf{n}=\mathbf{9 7} & \text { VAN } \mathbf{n}=\mathbf{4 4} & \mathbf{L Z D} \mathbf{n}=\mathbf{5 3} & \mathbf{p} \\ \text { Cure } & 65(67.0) & 26(59.1) & 39(73.6) & .23 \\ \text { Failure } & 25(25.8) & 15(34.1) & 10(18.9) & \\ \text { Indeterminate } & 7(7.2) & 3(6.8) & 4(7.5) & \end{array}$

Microbiological effectiveness in the clinically evaluable population*

\begin{tabular}{lllll} 
Eradication & $60(61.9)$ & $23(52.3)$ & $37(69.8)$ & .02 \\
Persistence & $8(8.2)$ & $2(4.5)$ & $6(11.3)$ & \\
Indeterminate & $29(29.9)$ & $19(43.2)$ & $10(18.9)$ & \\
\hline
\end{tabular}

*Documented diagnosis of GPC infection 
TABLE 7. Reason for treatment discontinuation

\begin{tabular}{lllll}
\hline $\mathbf{n}(\%)$ & Total $\mathbf{n}=\mathbf{1 4 7}$ & $\begin{array}{l}\text { VAN } \\
\mathbf{n = 6 8} \\
\text { (Group A) }\end{array}$ & $\begin{array}{l}\text { LZD } \\
\mathbf{n = 7 9} \\
\text { (Group B) }\end{array}$ & P \\
Clinical cure & $73(49,7)$ & $29(42,6)$ & $44(55,7)$ & .04 \\
Clinical failure & $33(22,4)$ & $20(29,4)$ & $13(16,5)$ & .07 \\
Adverse effects & $5(3,4)$ & $5(7,4)$ & $0(0,0)$ & .02 \\
No GPC infection & $15(10,2)$ & $8(11,8)$ & $7(8,9)$ & .37 \\
Treatment downtitration & $14(9,5)$ & $5(7,4)$ & $9(11,4)$ & .29 \\
Indeterminate & $7(4,8)$ & $1(1,5)$ & $6(7,6)$ & .08 \\
\hline
\end{tabular}




\section{Figure 1}

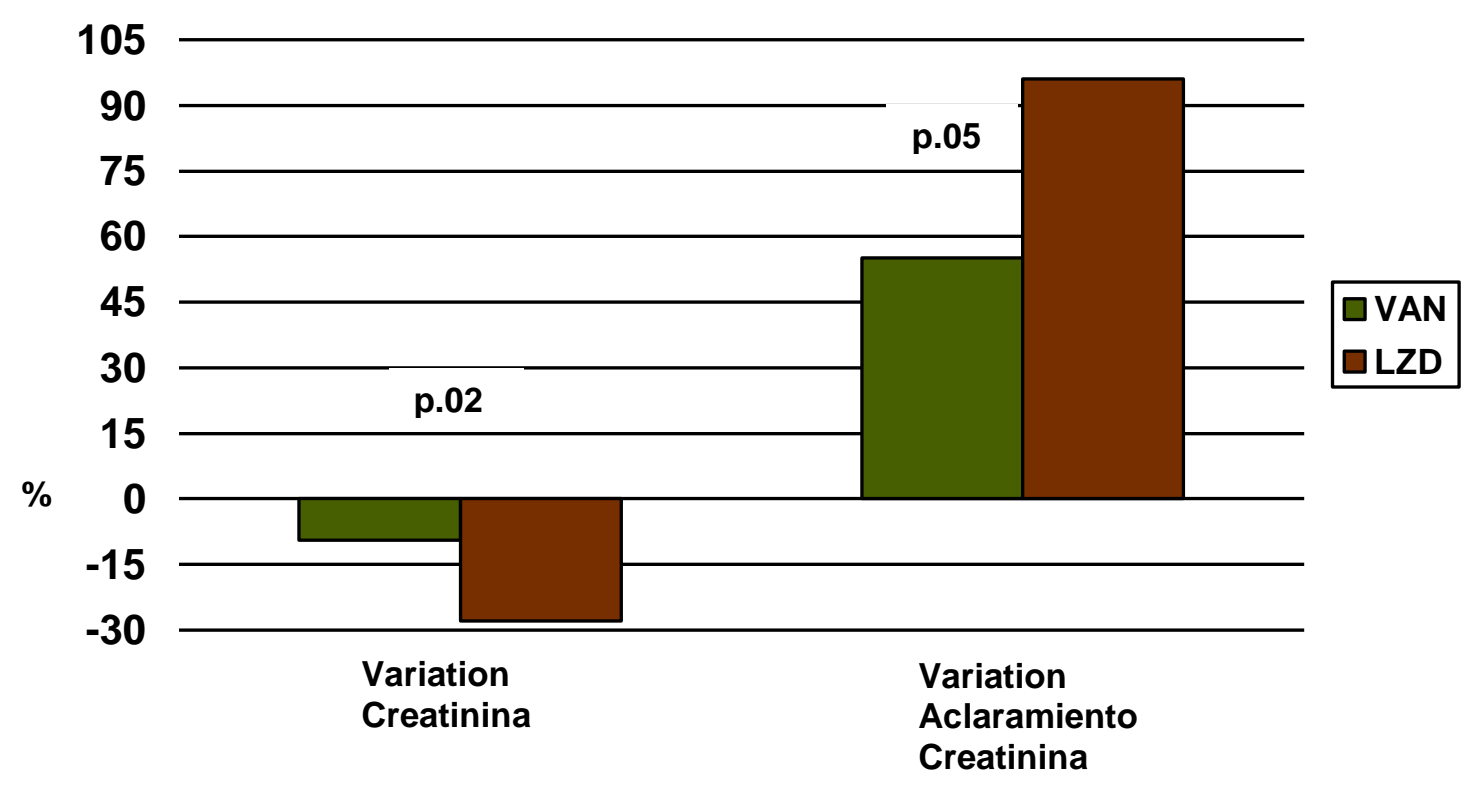

